\title{
1 Causes of death in newborn C57BL/6J mice
}

2 Sara Capas-Peneda ${ }^{1,2}$, Gabriela Munhoz Morello ${ }^{1,2}$, Sofia Lamas ${ }^{2,3}$ I Anna S 3 Olsson ${ }^{1,2}$, Colin Gilbert ${ }^{4}$

$4{ }^{1}$ Laboratory Animal Science, IBMC - Instituto de Biologia Molecular e Celular, 5 Universidade do Porto, Rua Alfredo Allen 208, 4200-135 Porto, Portugal (SCP, GMM, $6 \quad$ IASO)

7 2i3S - Instituto de Investigação e Inovação em Saúde, Universidade do Porto, Rua

8 Alfredo Allen 208, 4200-135 Porto, Portugal (SCP, GMM, SL, IASO)

$9 \quad{ }^{3}$ Animal Facility, IBMC - Instituto de Biologia Molecular e Celular, Universidade do 10 Porto, Rua Alfredo Allen 208, 4200-135 Porto, Portugal (SL)

Corresponding author:

Colin Gilbert

Biological Support Unit

Babraham Institute, Babraham Hall, Cambridge, CB22 3AT, United Kingdom

\section{E-mail address: colin.gilbert@babraham.ac.uk}

Telephone number: +441223496532 


\section{Abstract}

Neonatal mortality in wild-type laboratory mice is an overlooked welfare and financial problem in animal facilities around the world. Causes of death are often not reported and its causes remain unknown.

In this study, 324 newborn pups from two breeding colonies of healthy wildtype

C57BL/6 mice underwent post-mortem analysis with special focus on obtaining proof of life after birth, evaluation of stomach contents and observation of congenital abnormalities that could compromise survival.

Based on a combination of lung morphology findings, outcome of lung float test, stomach contents and brown adipose tissue colouration, $21.6 \%$ of the pups found dead were considered stillbirths. Of the livebirths, only $3.2 \%$ were observed to have milk inside the stomach, indicating successful suckling. Congenital abnormalities were diagnosed only in a small fraction of the pups analysed. These results suggest that starvation was the most common cause of death, followed by stillbirth.

\section{Keywords}

Neonatal mortality, Mouse, causes of death, C57BL/6J

High rates of pre-weaning mortality in laboratory mice are a widespread issue among animal facilities worldwide. This represents a major welfare problem ${ }^{33}$, a significant financial burden through lowered productivity and has an impact on the 3 Rs by increasing the number of animals needed and used for breeding.

Rates of perinatal mortality are reported as higher in inbred strains, especially in C57BL/6 mice, where they can reach $50 \%^{19}$. Attention to morbidity and mortality in newborn mice occurs primarily in the context of phenotyping genetically modified 
mice $^{2,29,45}$. In contrast, knowledge about causes of neonatal death in breeding colonies of healthy wildtype mice is limited and currently there are no agreed published guidelines or strategies to address this issue.

Mice are an altricial species and pups are dependent on parental care within a maternal nest during the first phase of their lives. The pups are born helpless, relatively immobile, blind, hairless, capable of suckling but not able to otherwise fend for themselves. They possess a very limited ability to produce heat by non-shivering thermogenesis using brown adipose tissue $(B A T)^{6,18}$. Consequently, major causes of neonatal mortality and low viability could be related to failures of parental care, such as predation, starvation and hypothermia in addition to birthing accidents, congenital defects and infectious processes.

Wild mice are communal nesters and females often share duties in the care for the young ${ }^{49}$. This characteristic is maintained in laboratory mice and is often exploited by housing mice in breeding trios, which allows for increases in the number of pups per cage $^{47}$ and individual pup growth ${ }^{15,16}$. However, this social conformation is more prone to litter overlap ${ }^{3}$, the existence of a previous litter inside the cage, which is associated with higher neonatal mortality 3 .

There is a widespread opinion amongst laboratory mouse care staff that dams often kill their pups (infanticide) due to observations of entire litters disappearing or to finding partially eaten pups (cannibalism). Cannibalism is agreed to be a common occurrence in rodents, but actual observations of infanticide are rare ${ }^{48}$.

The occurrence of congenital malformations incompatible with life could also play a role in neonatal mortality and these are typically related to the strain. The most 
common congenital malformations in C57BL/6J mice are hydrocephalus and microphtalmia ${ }^{4}$, not directly related to neonatal survival.

C57BL/6J mice are the most used inbred strain in biomedical research, as a wild-type and also as background strain to produce genetically modified lines. Of the over 2.7 million genetically modified mice used in research in the EU in $2017^{10}$, the majority are expected to be on a C7BL6/J background. Identifying the major causes of perinatal mortality in this strain is crucial to develop preventive strategies for mouse breeding, but also in the context of phenotyping genetically modified mice, so that pathologies related to the background strain can be distinguished from those related to the genetic modification.

Neonatal mice are often not subject to a post-mortem analysis perhaps due to a lack of proper guidelines. To our knowledge, this paper provides the first systematic report of post-mortem findings in neonatal ( 0 to 4 days old) wild-type inbred mice found dead in laboratory animal facilities during routine inspection.

\section{Materials and Methods}

\section{Ethical statement}

Animals examined in this study originated from breeding colonies of healthy wild-type mice in two licensed laboratory animal breeding facilities. No animals were generated solely for the purpose of this study.

All breeding was done according to the UK and Portuguese legislation (Home Office Regulations (Animal Scientific Procedures Act 1986) and Decreto-Lei 113/2013) and 
Directive 2010/63/EU of the European Parliament following the 3R's principle of Replacement, Reduction, and Refinement.

\section{Animals and housing}

Breeding mice C57BL/6J were housed in two different animal facilities: F1 (i3S Animal Facility- Institute for Research and Innovation in Health, Porto, Portugal), and, F2 (Biological Support Unit - Babraham Institute, Cambridge, UK). Genetic integrity was maintained by breeding stock replacement every ten generations either by obtaining new stock directly from the supplier (The Jackson Laboratory) or rederivation from frozen embryos.

Each facility bred mice for research according to EU and national law governing animal research and had the necessary approvals. All pups collected were from litters from the regular breeding programs of the respective facility and no extra breeding occurred for the purposes of this paper.

F1 - Breeding pairs and trios were maintained under SPF conditions in conventional static cages (Pairs: 1264C Type II @, Tecniplast, Italy, 268 × 215 x 141 mm; Trios: 1290D Type III @), Tecniplast, Italy, 425 × 276 x $153 \mathrm{~mm}$ ) with standard feed (Tecklad Global Diet Rodent 2014S, Italy) and water ad libitum obtained by reverse osmosis, filtered and UV irradiated. Each breeding cage was provided with a paper towel, a cardboard shelter (Des. Res. ${ }^{\text {TM }}$, LBS Biotechnology, UK) and corncob bedding (Scobis duo, Mucedola, Italy) . The room temperature was maintained between 20$24^{\circ} \mathrm{C}$ and relative humidity between $45-55 \%$ with a $12: 12$ light/dark photoperiod with no twilight.

F2 - Breeding pairs and trios were housed in individually ventilated cages (GM500 Filter@, Tecniplast, Italy; $\mathrm{L} \times \mathrm{W} \times \mathrm{H}, 391 \times 199 \times 160 \mathrm{~mm}$ ), mounted on a ventilated 
holding unit (DGM Sealsafe Plus Rack@, Tecniplast, Italy). Cleaned cages were automatically dispensed with an average of $48 \mathrm{~g}$ of soft wood flakes bedding (EcoPure Chips 6 Premium@, Datesand, UK) and $7.5 \mathrm{~g}$ of white paper rolls (Enrich-n'Nest@), Datesand, UK) as nesting material. Cages had either a mouse loft (Tecniplast, Italy) or a red polycarbonate tunnel (International Product Supplies Ltd, United Kingdom; L $\times \varnothing, 98.55 \times 50.80 \mathrm{~mm}$ ) suspended from the grid lid, to provide in each case enrichment and a refuge in the event of a cage flood. Room temperature was maintained at $20-24{ }^{\circ} \mathrm{C}$, relative humidity at $45-65 \%$ and a $12: 12 \mathrm{~h}$ light regime with lights gradually switched on from 07:00. Standard food pellets (CRM (P) Vacuum Pack, Dietex International Ltd., UK) and filtered water obtained by reverse osmosis and ultraviolet irradiation were provided ad libitum.

\section{$\underline{\text { Pup collection and cage inspection }}$}

324 pups found dead were collected between May 2018 and September 2019 in Facility $1(n=167)$ and between October 2019 and January 2020 in Facility $2(n=157)$. Whenever a dead pup was found, it was collected, inspected, identified and put inside a plastic bag for later analysis.

In Facility 1, breeding cages were inspected daily for the occurrence of births and pup counting between the day the female was confirmed as pregnant through abdominal swelling until day four after birth. Cages were removed from the rack and opened inside a laminar flow cabinet. Pups were counted with minimal manipulation or nest disturbance.

In Facility 2 the procedure was the same with the exception of the adults being marked with a sterile surgical grade marker every two days (avoiding the day of parturition) as 
a part of a behavioural study on maternal behaviour to allow easy identification in video recordings, a procedure that lasted approximately 20 seconds for each animal.

In both facilities, cage inspection was performed by the same researcher at $10 \mathrm{~h} \pm 1 \mathrm{~h}$.

Dead pups were also collected by technicians when found on daily inspection of breeding cages, using the same technique.

\section{Post-mortem inspection}

143 Pups collected were refrigerated $(n=171)$ or frozen $(n=153)$ immediately until postmortem analysis. These were defrosted at room temperature on the day the postmortem analysis was performed. Fresh specimens were analysed within 4 hours of collection.

The necropsy protocol consisted of an external and internal inspection. The external inspection evaluated general condition, skin integrity and occurrence of acquired lesions such as bruises or wounds. Congenital abnormalities such as cleft palate, microphtalmia, alterations of head shape or limbs were recorded, as were the appearance of the umbilicus and presence of fragments of foetal membranes.

Internal inspection was performed under a stereomicroscope. This was initiated by performing skin incision along both abdominal and thoracic cavities; access to the abdominal cavity was gained by performing a circular incision along the abdominal wall. Attention was given to the presence and appearance of all internal organs and stomach contents were evaluated as well. To perform the inspection of the thoracic cavity, a portion of the thoracic wall was removed. Lungs morphology was evaluated and a lung fragment was removed in order to perform a lung float test, using the liver as a control. The results of this test could be correlated with the content of the stomach. 
The appearance of interscapular BAT (coloration, dimensions and condition of blood vessels) was recorded.

\section{Lung morphology and lung float test}

Lung morphology was evaluated for degree of inflatedness, colouration and aeration. A lung float test was performed by removing a fragment of a lung lobe and a same size fragment of liver (as control for decomposition ${ }^{32,38}$ ) and putting both inside an Eppendorf tube filled with water. Whether the fragments sank or floated was recorded.

\section{Evaluation of stomach contents}

The level of distension of the stomach was evaluated and a small incision was made along the greater curvature. Stomach contents or lack thereof were recorded. Air was recorded whenever air bubbles where visible inside the stomach with or without other contents and some distension could be observed.

\section{Determination of stillbirths}

Results of the lung float test were correlated with macroscopical analysis of the lungs, stomach contents and BAT.

A pup was considered a stillbirth when all the 8 criteria presented in Table 1 were fulfilled simultaneously. Any pup that did not meet all criteria were considered livebirth or, in the absence of any organ, not conclusive.

\section{Brown adipose tissue}

BAT in the interscapular area was characterized in terms of its presence/absence, colouration (brown-pink or brown-yellow), presence of visible blood vessels and dimensions. 


\section{Results}

\section{Population characteristics}

324 pups originating from a total of 154 litters of a population composed of breeding trios and pairs parities between 1 and 11 (Table 2).

\section{Lung evaluation}

Lung float tests were performed in 321 pups. $65 \%$ of the lungs tested floated and $35 \%$ sank. All control liver fragments sank.

Lung colouration was generally pale pink for sinking lungs, and pink or dark pink for floating lungs, the latter possibly related to hypostatic blood accumulation. Since dead pups were collected whenever found, decomposition could be expected in some specimens. These commonly partially floated but all had signs of aeration and inflatedness with observable air bubbles in the pulmonary parenchyma.

Two pups presented severely congested lungs with a grey colouration and the lung fragment sank, although some level of lung inflation or aeration was observed. One of these pups also showed blood clots inside the thoracic cavity.

198 Three pups were not evaluated due to missing lungs (cannibalism).

Stomach contents evaluation

Stomach contents evaluation of all pups are summarised on table 3. 
Only 8 (2.5\%) pups had milk in their stomachs and only two pups had a stomach filled with milk. Only one of these, a pup from a cage without an older litter, presented traumatic lesions (neck echimosis and bruises in the hindlimbs).

\section{Stillbirths and Livebirths}

Overall percentages of stillbirths and livebirths are illustrated in Figure 1. Seventy (21.6\%) pups were considered stillbirths, according to the criteria in Table 1. Of these, $17(24.3 \%)$ also presented amniotic fluid inside the thoracic cavity, $13(18.6 \%)$ presented traumatic lesions of which one was partially eaten. Internal haemorrhage was observed in 2 pups and possibly was related to trauma during birth. 2 pups presented intact umbilical cords (Figure 2) and 6 pups presented abnormally small size (Figure 4).

$251(77.5 \%)$ of the pups inspected were considered livebirths, with all lungs showing some degree of aeration or inflation. These pups were found $0,8 \pm 0,83$ days after birth. Stomach contents were: milk $(n=8 ; 3.2 \%)$, amniotic fluid $(n=29 ; 11.6 \%)$, air $(n=133 ; 53.0 \%)$, empty $(n=69 ; 27.5 \%)$ and decomposed or stomachs missing $(n=16$; 6.4\%). Traumatic lesions were observed in $63(25.1 \%)$ of livebirths and $18(7.2 \%)$ were partially eaten. Internal bleeding was diagnosed in 14 pups by observation of blood inside the abdominal cavity.

$3(0.9 \%)$ pups could not be evaluated due to cannibalism as some of the internal organs (including the lungs) were missing. 


\section{Brown adipose tissue}

BAT was present in all of the pups inspected. The tissue colouration, blood vessel and dimensions varied according to the age of the pups. On day 0 pups usually presented brown-yellow BAT with visible blood vessels, by day 1, brown-pink BAT was observed with variably reduced appearance of blood vessels.

\section{Pathological findings and traumatic lesions}

231

232

All gross pathological findings are summarized on Table 4. Overall, 79 (24.4\%) pups presented some kind of traumatic lesion, including bite wounds and bruises (Figure 57). Bite wounds include cannibalism events where parts of a pup were missing and small incised or puncture wounds probably caused by biting.

205 (63.3\%) pups were collected from cages where there was an older litter present, from these $23.4 \%$ (48) presented traumatic lesions. While from the group of pups that were collected from cages with no previous litter ( $n=119 ; 36.7 \%), 26.1 \%$ (31) of these showed traumatic lesions. Excluding bite wounds, the incidence of traumatic lesions such as bruises in the overlap group was $20 \%$ (41) and $16 \%$ (19) in the no overlap group.

Regarding stomach contents, in the overlap group, 5 (2.4\%) pups presented milk inside stomach and $140(68.3 \%)$ presented empty stomachs or presence of air inside the stomach. In the no overlap group, 3 (2.5\%) pups presented milk inside the stomach and $52(43.7 \%)$ presented empty stomachs or presence of air inside the stomach.

Lesions involving structures of the head such as the lips, jaw or tongue were present in 9 (3.6\%) pups considered live-born. Internal haemorrhage was seen in a total of 13 (4.0\%) pups with significant amounts of blood within the abdominal cavity; of these 11 had evidence of being live-born. 
Hepatomegaly and cardiomegaly were seen in one case. Two pups presented anasarca (Figure 3), hydrothorax and ascites.

251

\section{$\underline{\text { Congenital malformations }}$}

No pups inspected showed palate malformations. Microphtalmia was observed in one pup. Hydrops fetalis was observed in 2 pups $(0,6 \%)$ which showed anasarca, hydrothorax and ascites (Figure 3). Skin defects localized in the head and the umbilical region were observed in two pups $(0,6 \%)$ (Figure 8$)$.

\section{Discussion}

In this study, $21.6 \%$ of the pups found dead were considered stillbirths and $77.5 \%$ livebirths. Among the livebirths, only 3.2\% presented with milk inside the stomach, indicating successful suckling. Congenital malformations were very rare, whereas traumatic lesions were found in $24.4 \%$ of all the pups.

One hypothesis for neonatal death of live born pups would be that impairments to maternal behaviour could compromise suckling. Neonatal pups, as all mammals, are dependent on the ingestion of colostrum and milk for survival, Without being fed, neonates are only able to survive for 24 hours $^{30}$. The first suckling event and a successful nipple attachment is therefore critical. For this, mutual dam and pup recognition is essential. This process seems to be mediated by odour cues that are present in the nipples of the dam and are recognized by the pups ${ }^{1}$. Since pups are relatively immobile at birth maternal attention is required for a successful nursing event. Ultrasonic vocalizations (USVs) play a major role in the communication between the dam and pups and also in the formation of the mother-infant bonding along with olfactory and visual stimuli ${ }^{36}$ so it is likely that they will also play a major role in pup survival. 
273 Pups are highly vocal in the first two weeks after birth, producing audible calls in 274 situations such as rough handling ${ }^{13}$ and, most notably, USVs that are emitted by pups when in distress (isolation and cold stress) eliciting a maternal response from the dam, such as pup retrieval ${ }^{7}$. These are characterized by having frequencies between 30-90 $\mathrm{kHz}$ and being emitted in an increasing rate during the first 6-7 days after birth and gradually decreasing until complete disappearance at two weeks after birth ${ }^{8}$. USVs emission is needed to ensure successful communication and, thus, a maternal response. Further evidence of their role in pup survival is given due to the finding that an increase in serum prolactin levels occurs as a response to USVs in lactating rats ${ }^{14}$.

C57BL/6 mice are known to suffer from age-related hearing loss that starts to develop as soon as 10 weeks of age and initially affects hearing of higher frequencies ${ }^{20}$. Furthermore, sex differences have been reported with females presenting a more severe degree of hearing loss when compared to males of the same age ${ }^{17}$. This hearing impairment can potentially have an impact on maternal care and compromise pup survival by decreasing maternal responsiveness and predisposing to death by hypothermia or starvation. Further investigations are needed on this topic.

More than half $(53,4 \%)$ of livebirths presented air inside the stomach, either as the only content $(50,1 \%)$ or associated with milk $(3,3 \%)$. This finding could suggest that these pups tried to suckle but only air was ingested. Air inside stomach takes volume and could also impair the ingestion of milk and lead to malnutrition. The attempt to suckle and the ingestion of air suggests either a deficient lactation (maternal cause) or a failed attempt to nurse (neonatal cause).

For a successful attempt to suckle, pups need the necessary structures to be able to attach to the nipple and create negative pressure to ensure milk flow and ingestion. $\mathrm{A}$ 
failed attempt to suckle could be related to a deficient nipple attachment due to craniofacial deformities such as hard palate abnormalities ${ }^{39}$ or ankyloglossia ${ }^{35}$ that are generally associated with severe gastric distension. In this study, hard palate deformities and tongue immobility were not observed but further histologic analysis could be necessary to evaluate the presence of ankyloglossia. Furthermore, only two pups presented severe gastric distension.

A deficient lactation could also play a role. Milk production in mice can be influenced

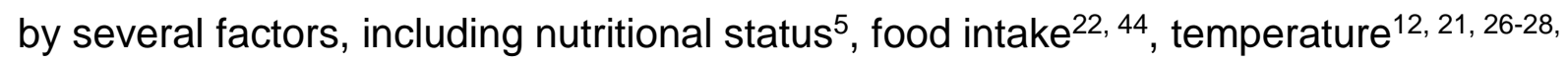
${ }^{46}$, litter size $\mathrm{e}^{24,25}$ and lactation number ${ }^{24}$. Pup stimulus after birth seems to play a major role since in previous studies differences in milk production were only found after the fourth day of lactation across different litter sizes ${ }^{25}$

In situations of litter overlap, an increase in temperature inside the nest can have a negative effect in milk production ${ }^{12}$. Furthermore, since female mice are known to nurse pups indiscriminately in communal nests ${ }^{11}$, it is possible that milk "theft" could occur due to competition from larger and more mobile older pups. However, our data show that the proportion of pups without milk in their stomach is the same for cages with overlapping litters as for cages with only one litter.

Infanticide is very rare in $\mathrm{B} 6$ mice $^{48}$, suggesting that the traumatic lesions observed should not generally be regarded as the cause of death. Bruises in different locations of the body were observed at a low frequency $(13 \%)$ varying in colour between red and blue, and sometimes associated with swelling. The timing of such lesions is difficult to determine but since their formation requires blood flow and some time for the lesion to appear, forensic pathologists agree that they should be normally regarded as indicators of an ante-mortem traumatic event, although it can happen post-mortem 
when greater force is applied ${ }^{42}$. Further histological and biochemical analysis could be helpful in timing these lesions ${ }^{31}$. However, the majority of the observed bruises were insufficient to be regarded as the cause of death, with the possible exception of those involving the lips, tongue or jaw that could have an impact on the ability to suckle. Of course, pups that have died and been entirely consumed are missing from this data set.

Internal haemorrhage was a rare observation in both live and stillbirths. In both cases, trauma would be required and blood loss would contribute to death. The occurrence in stillbirths is probably related to parturition issues ${ }^{45}$.

Congenital malformations such as cleft palate, hydrocephalus or other gross malformations in internal organs that could impair survival were not directly observed, although a skin defect around the umbilical area that could potentially expose internal organs and compromise survival was observed in one pup (Figure 8). Another pup presented signs of cardiac failure at 2 days of age (cardiomegaly and hepatomegaly possibly related to a cardiovascular malformation. Two pups presented anasarca, hydrothorax and ascites, all lesions compatible with fetal hydrops ${ }^{37}$. Microphtalmia was also observed in one pup.

Cannibalism is common in laboratory mice and infanticide has been attributed as a cause of neonatal death in laboratory animal house facilities ${ }^{43,48}$ although our recent data suggests this is less common than previously reported ${ }^{3}$. In the present study, only one pup from 324 was clearly the victim of trauma ante-mortem sufficient to cause death by the presence of incised wounds, facial bruises with visible oedema and blood inside the stomach. 
Identification of stillbirths has always been a challenge ${ }^{40}$ and the lung floatation test is the subject of debate ${ }^{38}$ as tissue decomposition can lead to confounding effects. Fortunately, in laboratory animal house facilities environmental conditions are highly standardized and the animals are inspected at least once every day. Therefore decomposition processes are limited and the rate relatively standardised. A lung float test and evaluation of stomach contents to identify stillbirths in breeding transgenic mice has been reported ${ }^{9}$. However, performance of the lung float test alone can lead to erroneous conclusions ${ }^{34}$. We therefore used the liver as a control for air produced by decomposition ${ }^{32}$. When combined with a careful evaluation of the lung morphology, stomach contents and brown adipose tissue, a reliable predictor of post-partum viability may be obtained. Further evidence could be obtained by observation of the umbilical cord (cicatrisation versus the presence of an intact umbilical cord and/or foetal membranes). Presence of amniotic fluid inside the stomach indicates either a stillbirth or a death immediately after birth because foetuses swallow amniotic fluid while inside the uterus ${ }^{23}$ but gastric emptying occurs as much as twice per hour in neonates $^{41,50}$.

In summary, the findings presented here show that the commonest cause of death in neonatal C57BL/6 laboratory mice is starvation since the majority of livebirths had no milk in their stomachs. Secondary reasons for a failure to suckle should be a key subject for future research. Stillbirth was the second most common reason for death, although the causes behind this could not be identified in most cases. Contrary to expectations, active infanticide by adults was extremely rare. 
The authors thank all staff at the i3S Animal Facility and the Babraham Institute

national infrastructure PPBI - Portuguese Platform of Bioimaging (PPBI-POCI-01-

0145-FEDER-022122).

\section{Declaration of conflicting interests}

The author(s) declared no potential conflicts of interest with respect to the research, authorship, and/or publication of this article.

\section{Funding}

This work was financed by FEDER - Fundo Europeu de Desenvolvimento Regional funds through the COMPETE 2020 - Operacional Programme for Competitiveness and Internationalisation (POCI), Portugal 2020, and by Portuguese funds through FCT FEDER-016591).

\section{References}

1. Al Aïn S, Belin L, Schaal B, et al. How does a newly born mouse get to the nipple? odor substrates eliciting first nipple grasping and sucking responses. Developmental Psychobiology 2013; 55: 888-901.

2. Bolon B. Pathology of the Developing Mouse: A Systemic Approach. 1st ed. Boca Raton, FL, USA: CRC Press, 2015.

389 3. Brajon S, Munhoz Morello G, Teixeira MS, et al. Social environment as a cause of litter loss in laboratory mouse: A behavioural study. Applied Animal Behaviour Science 2019; 218: 104827. Davisson MT, Quimby FW, et al. (eds) The Mouse in Biomedical Research (Second Edition). Burlington: Academic Press, 2007, pp.623-717. mice by inducing prolactin resistance. Scientific Reports 2016. 
bioRxiv preprint doi: https://doi.org/10.1101/2020.02.25.964551; this version posted February 26,2020 . The copyright holder for this preprint (which was not certified by peer review) is the author/funder, who has granted bioRxiv a license to display the preprint in perpetuity. It is made available under aCC-BY-NC-ND 4.0 International license.

6. Cannon B and Nedergaard J. Brown Adipose Tissue: Function and Physiological Significance. Physiological Reviews 2004; 84: 277-359.

7. Ehret G. Categorical perception of mouse-pup ultrasounds in the temporal domain. Animal Behaviour 1992; 43: 409-416.

8. Elwood RW and Keeling F. Temporal organization of ultrasonic vocalizations in infant mice. Developmental Psychobiology 1982; 15: 221-227.

9. Embree-Ku M and Boekelheide K. Absence of p53 and FasL Has Sexually Dimorphic Effects on Both Development and Reproduction. Experimental Biology and Medicine 2002; 227: 545-553. 10. European C. 2019 report on the statistics on the use of animals for scientific purposes in the Member States of the European Union in 2015-2017 2020. European Comission.

11. Ferrari $\mathrm{M}$, Lindholm $A K$ and König $B$. The risk of exploitation during communal nursing in house mice, Mus musculus domesticus. Animal Behaviour 2015; 110: 133-143.

12. Gamo Y, Bernard A, Troup C, et al. Limits to sustained energy intake XXIV: impact of suckling behaviour on the body temperatures of lactating female mice. Scientic Reports 2016.

13. Hahn ME and Lavooy MJ. A Review of the Methods of Studies on Infant Ultrasound Production and Maternal Retrieval in Small Rodents. Behavior Genetics 2005; 35: 31-52.

14. Hashimoto H, Saito TR, Furudate S-i, et al. Prolactin Levels and Maternal Behavior Induced by Ultrasonic Vocalizations of the Rat Pup. Experimental Animals 2001; 50: 307-312.

15. Heiderstadt KM and Blizard DA. Increased Juvenile and Adult Body Weights in BALB/cByJ Mice Reared in a Communal Nest. Journal of the American Association for Laboratory Animal Science 2011; 50: 484-487.

16. Heiderstadt KM, Vandenbergh DJ, Gyekis JP, et al. Communal Nesting Increases Pup Growth But Has Limited effects on Adult Behaviour and Neurophysiology in Inbred Mice. Journal of the American Association for Laboratory Animal Science 2014; 53: 152-160.

17. Henry KR. Sex- and age-related elevation of cochlear nerve envelope response (CNER) and auditory brainstem response (ABR) thresholds in C57BL/6 mice. Hearing Research 2002; 170: 107115.

18. Hull D. Thermoregulation in Young Mammals. In: Whittow GC (ed) Special Aspects of Thermoregulation. New York, NY: Academic Press, Inc,, 1973, pp.167-200.

19. Inglis CA, Campbell ER, Auciello SL, et al. Effects of Enrichment Devices on Stress-related Problems in Mouse Breeding. Animal Welfare Enhancement Reports John hopkins Center for Alternatives to Animal Testing 2004: 1-9.

20. Ison JR, Allen PD and O'Neill WE. Age-Related Hearing Loss in C57BL6J Mice has both Frequency-Specific and Non-Frequency Specific Components that Produce a Hyperacusis-Like exaggeration of the Acoustic Startle Reflex. JARO 2007; 8: 539-550.

21. Johnson MS and Speakman JR. Limits to sustained energy intake V. Effect of cold-exposure during lactation in Mus musculus. The Journal of Experimental Biology 2001; 204: 1967-1977.

22. Johnson MS, Thomson SC and Speakman JR. Limits to sustained energy intake I. Lactation in the laboratory mouse Mus musculus. The Journal of Experimental Biology 2001; 204: 1025-1935. 23. Kleven GA and Ronca AE. Prenatal behavior of the C57BL/6J mouse: A promising model for human foetal movement during early to mid-gestation. Developmental Psychobiology 2009; 51: 8494.

24. Knight $\mathrm{CH}$, Maltz E and Docherty AH. Milk yeld and composition in mice: Effects of litter size and lactation number. Comp Biochem Physiol 1986; 84: 127-133.

25. Konig B, Riester J and Markl H. Maternal care in house mice (Mus musculus) : II. The energy cost of lactation as a function of litter size. J Zool 1988; 246: 195-210.

26. Król E, Murphy M and Speakman JR. Limits to sustained energy intake. X. Effects of fur removal on reproductive performance in laboratory mice The Journal of Experimental Biology 2007; 210: 4233-4243.

27. Król E and Speakman JR. Limits to sustained energy intake VI. Energetics of lactaction in laboratory mice at thermoneutrality. The Journal of Experimental Biology 2003; 206: 4255-4266. 
28. Król E and Speakman JR. Limits to sustained energy intake VII. Milk energy outputin laboratory mice at thermoneutrality. The Journal of Experimental Biology 2003; 206. 29. Kulandavelu S, Qu D, Sunn N, et al. Embryonic and Neonatal Phenotyping of Genetically Engineered Mice. ILAR Journal 2006; 47: 103-117. starvation period. Nature 2004; 432: 1032-1036.

31. Li N, Du Q, Bai R, et al. Vitality and wound-age estimation in forensic pathology: review and future prospects. Forensic Sciences Research 2018: 1-10.

32. Mazuchowski EL, Franco DM, Berran PJ, et al. The Virtual Hydrostatic Test. Am J Med Pathol 2017; 38: 24-28.

33. Mellor DJ and Stafford KJ. Animal welfare implications of neonatal mortality and morbidity in farm animals. The Veterinary Journal 2004; 168: 118-133.

34. Milroy C. Neonatal Deaths, Infanticide, and the Hydrostatic (Floatation) Test: Historical Perspectives. Academic Forensic Pathology 2012; 2: 338-345.

35. Morita H, Mazerbourg S, Bouley DM, et al. Neonatal Lethality of LGR5 Null Mice Is Associated with Ankyloglossia and Gastrointestinal Distension. Molecular and Cellular Biology 2004; 24: 9736-9743.

36. Nagasawa $\mathrm{M}$, Okabe $\mathrm{S}$, Mogi $\mathrm{K}$, et al. Oxytocin and mutual communication in mother-infant bonding. Frontiers in Human Neuroscience 2012; 6.

37. Nagy A and Malcomson RDG. Fetal Hydrops. In: Khong TY and Malcomson RDG (eds) Keeling's Fetal and Neonatal Pathology. 5th Edition ed.: Springer, 2015, pp.299-328.

38. Ostendorf A-LG, Rothschild MA, Müller AM, et al. Is the lung floating test a valuable tool or obsolete? A prospective autopsy study. Int J Legal Med 2013; 127: 447-451.

39. Pauws $E$, Hoshino A, Bentley $L$, et al. Tbx22null mice have a submucous cleft palate due to reduced palatal bone formation and also display ankyloglossia and choanal atresia phenotypes. Hum Mol Genet 2009; 18: 4171-4179.

40. $\quad$ Philips B and Ong BB. "Was the Infant Born Alive?" A Review of Postmortem Techniques Used to Determine Live Birth In Cases of Suspected Neonaticide. Academic Forensic Pathology International 2018; 8: 874-893.

41. Sase M, Miwa I, Sumie M, et al. Gastric emptying cycles in the human fetus. American Journal of Obstetrics and Gynecology 2005; 193: 1000-1004.

42. Saukko P and Knight B. The Pathology of Wounds. Knight's Forensic Pathology. 4th Edition ed. Boca Raton, FL: CRC Press, 2016, pp.133-165.

43. Schmidt J, Kosztolányi A, Tokolyi J, et al. Reproductive asynchrony and infanticide in house mouse breeding communally. Animal Behaviour 2015; 101: 201-211.

44. Speakman JR, Gidney A, Bett J, et al. Limits to sustained energy intake IV. Effect of variation in food quality on lactating mice Mus musculus. The Journal of Experimental Biology 2001; 2014: 1957-1965.

45. Turgeon B and Meloche S. Interpreting Neonatal Lethal Phenotypes in Mouse Mutants: Insights Into Gene Function and Human Diseases. Physiological Reviews 2009; 89: 1-26.

46. Valencak TG, Wright $P$, Weir A, et al. Limits to energy intake. XXI. Effect of exposing the mother, but not her pups, to a cold environment during lactation in mice. The Journal of Experimental Biology 2013; 216: 4326-4333.

47. Wasson K. Retrospective Analysis of Reproductive Performance of Pair-bred Compared with Trio-bred Mice. Journal of the American Association for Laboratory Animal Science 2017; 56: 190193.

48. Weber EM, Algers B, Hultgren J, et al. Pup mortality in laboratory mice - infanticide or not? Acta Veterinaria Scandinavica 2013; 55.

49. Weber EM and Olsson IAS. Maternal behaviour in Mus musculus sp.: A ethological review. Applied Animal Behaviour Science 2008; 114: 1-22. 
50. Welsh C, Jarrin J, Daneman A, et al. In vivo ultrasound assessment of gastric emptying in newborn mice. J Pediatr Gastroenterol Nutr 2015; 60: 322-326.

\section{Figure legends}

501

502

503

504

505

506
Fig. 1 - Numbers of stillbirths and livebirths with and without presence of milk inside the stomach.

Fig. 2 - Remains of foetal membranes and umbilical cord adhered to the skin.

Fig. 3 - Anasarca.

Fig. 4 - Stillbirth with kyphosis and abnormally small size.

Fig. 5 - Small wound left dorsal area of muzzle.

Fig. 6 - Cannibalism. Left portion of cranium and neck missing.

Fig. 7 - Two small puncture wounds medial area of right hindlimb.

Fig. 8 - Skin defect at the umbilical region with exposed abdominal viscera.

Fig. 10 - Hemoabdomen.

\section{Supplemental Files}

Original files of the post-mortem pictures are available on Supplemental File 1. 
TABLES

524

525

526

527

528

529

Table 1 - Criteria for stillbirth evaluation

Lung morphology

- No signs of aeration

- No signs of inflatedness

- Pale pink colouration

530

531

532

533

534

535

536

Lung float test

- Sinking lung fragment

- Sinking liver fragment

Stomach contents

- Presence of amniotic fluid inside stomach

- No air present

BAT colouration

- Brown-yellow

537

538

539

540

541

542

543

544

545

546

547

548

549

550

551

552 


\begin{tabular}{|c|c|c|}
\hline $\begin{array}{l}\text { Breeding } \\
\text { configuration }\end{array}$ & $\mathbf{n}$ & $\%$ \\
\hline Trios $\left(2 q+1{ }^{\lambda}\right)$ & 114 & 74 \\
\hline Pairs $\left(1 q+1 \delta^{\lambda}\right)$ & 40 & 26 \\
\hline Mortality & $\mathbf{n}$ & $\%$ \\
\hline $\begin{array}{l}\text { Litters from which all } \\
\text { pups died }\end{array}$ & 60 & 39 \\
\hline $\begin{array}{l}\text { Litters from which at } \\
\text { least one pup survived }\end{array}$ & 94 & 61 \\
\hline Parity distribution & $\mathbf{n}$ & $\%$ \\
\hline Parity 1 & 11 & 7.1 \\
\hline Parity 2 & 29 & 18.8 \\
\hline Parity 3 & 37 & 24.0 \\
\hline Parity 4 & 21 & 13.6 \\
\hline Parity 5 & 23 & 14.9 \\
\hline Parity 6 & 12 & 7.8 \\
\hline Parity 7 & 10 & 6.5 \\
\hline Parities 8-11 & 11 & 7.1 \\
\hline Parental age & Mean & SD \\
\hline Mother Age (days) & 165.9 & 56.8 \\
\hline Father Age (days) & 175.9 & 55.8 \\
\hline Parental age range & Youngest & Oldest \\
\hline $\begin{array}{l}\begin{array}{l}\text { Mother } \\
\text { (days) }\end{array} \\
\end{array}$ & 68 & 328 \\
\hline $\begin{array}{l}\begin{array}{l}\text { Father } \\
\text { (days) }\end{array} \\
\text { (dge }\end{array}$ & 77 & 317 \\
\hline
\end{tabular}

$554 n$-number of occurrences. \% - Percentage of occurrences. Mean - arithmetic mean.

$555 S D$ - Standard deviation. $q$ - Female. $\hat{\sigma}$ - Male 
\begin{tabular}{|l|}
\hline \multicolumn{1}{|l}{ Table 3 - Stomach contents } \\
\hline Contents $\mathrm{n}(\%)$
\end{tabular}

Air

138

Amniotic fluid

$(42.6 \%)$

Empty

Decomposed

$99(30.6 \%)$

Milk

$69(21.3 \%)$

Blood

Meconium

Fur

$9(2.8 \%)$

$8(2.5 \%)$

$1(0.3 \%)$

$1(0.3 \%)$

$1(0.3 \%)$

Missing

$10(3.1 \%)$

568

569

570

571

572

573

574

575

576

577

578

579

580

581

582

583

584

585

586

587 
Pathological findings

592

593

594

595

596

597

Organ

Finding

Heart

Cardiomegaly

Liver

Hepatomegaly

Liver

Thymus

Colour alterations

Eye

Petechiae

Spleen

Microphtalmia

Lungs

Colour alterations

Skin

Congestion

Congenital

(localized)

Systemic

Subcutaneous edema

(Anasarca)

Hydrothorax

Ascites

$2(0.6 \%)$

$2(0.6 \%)$

598

599

600

601

Traumatic Lesions

\begin{tabular}{|l|l|l|}
\hline Type of lesion & Localization & $\mathbf{n}(\%)$ \\
\hline Bruises & Head & $23(7.1 \%)$ \\
\hline & Limbs & $11(3.4 \%)$ \\
\hline & Abdomen & $4(1.2 \%)$ \\
\hline & Thorax & $2(0.6 \%)$ \\
\hline Bite wounds & Dorsal area & $3(0.9 \%)$ \\
\hline & Head & $21(6.5 \%)$ \\
\hline & Limbs & $10(3.1 \%)$ \\
\hline & Abdomen & $11(3.4 \%)$ \\
\hline & Thorax & $1(0.3 \%)$ \\
\hline
\end{tabular}

602 
2

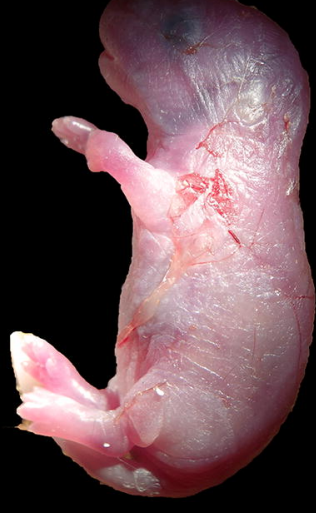

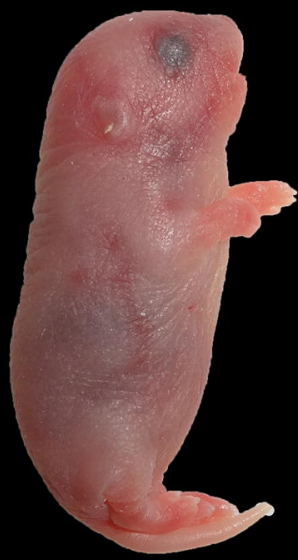

3

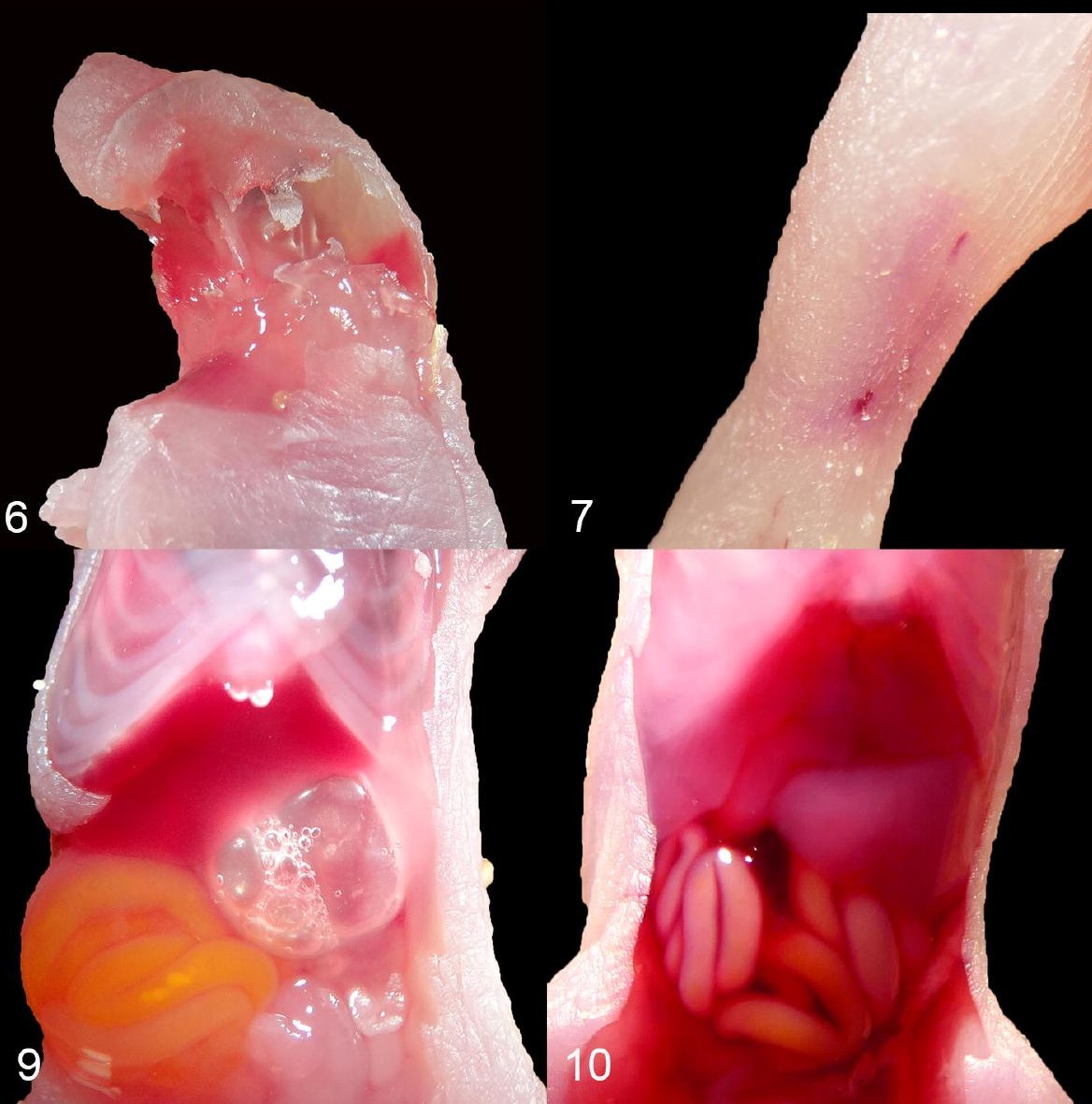




\section{Stillbirths vs Livebirths}

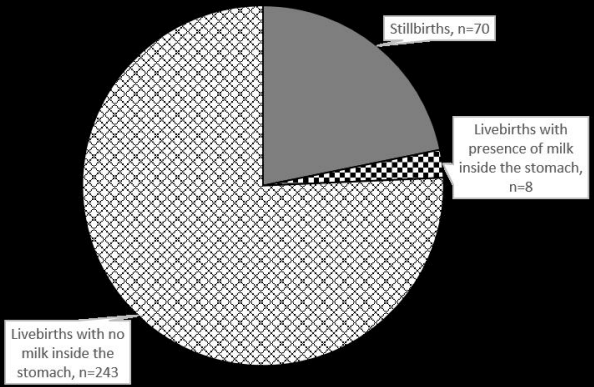

